\title{
OCCUPATIONAL EXPOSURE TO IONIZING RADIATION AND LENS OPACITY IN INTERVENTIONAL CARDIOLOGISTS
}

\section{JOANNA DOMIENIK-ANDRZEJEWSKA ${ }^{1}$, PAWEŁ KAŁUŻNY², GABRIELA PIERNIKํㅜ, and JOANNA JUREWICZ²}

\author{
Nofer Institute of Occupational Medicine, Łódź, Poland \\ ${ }^{1}$ Department of Radiological Protection \\ ${ }^{2}$ Department of Environmental Epidemiology
}

\begin{abstract}
Objectives: Interventional cardiologists (ICs) are occupationally exposed to low or moderate doses of ionizing radiation from repeated exposures. It is not clear whether these occupational conditions may affect their eye lens. Therefore, the risk of radiation-induced cataract in the cohort of Polish interventional cardiologists is analyzed in this paper. Material and Methods: The study group consisted of 69 interventional cardiologists and 78 control individuals occupationally unexposed to ionizing radiation. The eye lens opacities were examined using a slit camera and evaluated with Lens Opacities Grading System III. Cumulative eye lens doses were estimated retrospectively using a questionnaire including data on occupational history. Results: The average cumulative dose to the left and right eye lens of the ICs was $224 \mathrm{mSv}$ and $85 \mathrm{mSv}$, respectively. Nuclear opalescence and nuclear color opacities in the most exposed left eye were found in 38\% of the ICS for both types, and in $47 \%$ and $42 \%$ of the controls, respectively. Cortical opacities were found in 25\% of the ICS and $29 \%$ of the controls. Posterior subcapsular opacities were rare: about $7 \%$ in the ICs group and $6 \%$ in the control group. Overall, there was some, but statistically insignificant, increase in the risk for opacity in the ICs group, relative to the control group, after adjusting for the subjects' age, gender, smoking status and medical exposure (adjusted OR = 1.47, 95\% CI: 0.62-3.59 for the pooled "any-eye any-type" opacity). There was also no evidence for an increased opacity risk with an increase in the dose. Conclusions: The study found no statistically significant evidence against the hypothesis that the risk of cataract in the group of the ICs occupationally exposed to low doses of ionizing radiation is the same as in the control group. Nevertheless, the adverse effect of ionizing radiation still cannot be excluded due to a relatively small study sample size. Int J Occup Med Environ Health. 2019;32(5):663-75
\end{abstract}

Key words:

occupational exposure, ionizing radiation, cataract, low doses, cumulative eye lens doses, interventional cardiologists

\section{INTRODUCTION}

The cataract is a visual impairment manifesting itself in the opacity or cloudiness in the crystalline lens of the eye. Aging is the main risk factor for the cataract and the agerelated cataract is the most common form of this disease observed in the human population, usually after the age of 50-60 years, but opacities (the initial form of the cataract) can develop at an earlier age. In addition, there are also other known risk factors that can induce opacities formation (that later progress into cataract), such as female gender, genetic susceptibility, ionizing or UV radiation, diabetes and medical treatment with steroids [1]. While different studies provide inconsistent conclusions regarding smoking and alcohol consumption [2-5], it is a well-known fact that

\footnotetext{
Funding: this work was supported by Nofer Institute of Occupational Medicine in Lódź (grant No. IMP 16.8/2013-2015 entitled "Assessment of eye lens opacities in interventional cardiologists," grant manager: Joanna Domienik-Andrzejewska, Ph.D.) and by the Seventh Framework Programme (FP7) (grant No. 604984 entitled "European epidemiological study on radiation-induced lens opacities among interventional cardiologists," grant manager: Lara Struelens, Ph.D.).

Received: March 13, 2019. Accepted: July 11, 2019.

Corresponding author: Joanna Domienik-Andrzejewska, Nofer Institute of Occupational Medicine, Department of Radiological Protection, św. Teresy 8, Łódź 91-348, Poland (e-mail: joanna.domienik@imp.lodz.pl).
} 
a healthy diet, rich in antioxidants, including vitamin $\mathrm{A}$ and vitamin $\mathrm{C}$, and minerals, decreases the cataract risk [6-7]. Three types of cataract are distinguished in terms of the location of changes in the eye lens, i.e., nuclear (deep, near the optical axis of the lens), cortical (on and near the equatorial surface of the lens) and posterior subcapsular (PSC). According to the recent studies, there is an apparent lack of phenotypic conformity for the type of cataract which, together with multiple risk factors, makes the understanding of the mechanism of cataract formation challenging and still unclear. For example, PSC opacities were previously considered to be related to exposure to ionizing radiation (IR) but recent studies have confirmed that also cortical and nuclear opacities might develop after exposure to IR, as presented in the review by Jacob [8]. In addition, similar to IR, the use of steroids or the aging factor might cause opacities linked to PSC or nuclear changes, respectively.

There is no doubt that high-dose IR exposure causes cataract [9-10]. However, regarding low-dose exposure, the situation is not clear, in particular with respect to the associated risk and the level, or even the existence, of a dose threshold [11]. Therefore, further investigation of the effects of radiation on workers chronically exposed to low doses is still needed.

Interventional cardiologists (ICs) are subjected in their everyday occupational practice to repeated exposures to low doses of IR. Their cumulative doses range from $<0.1 \mathrm{~Sv}$ up to $2 \mathrm{~Sv}$, depending on the years of practice and workload [12]. In the case of high workload and long occupational lifetime, the dose estimate can reach 9-10 Sv (although with very low probability) [13]. Therefore, the exposure levels of ICs cover a broad range of doses around the cataract threshold dose of $0.5 \mathrm{~Gy}$ [14]. This fact makes this professional group an important population for studies of radiation induced-opacities related to low doses, and for assessment of their occupational safety.

The aim of this study is to analyze the association between eye lens opacities and IR among a group of Polish inter- ventional cardiologists in the extended cohort, relative to the previous pilot study conducted by the authors presenting only the characteristics of a partial study population and unexposed controls [15]. This enlarged cohort has been included in the European cohort of ICs recruited for the analysis of the dose-effect relationship within the EURALOC project (the European epidemiological study on radiation-induced lens opacities among interventional cardiologists). Moreover, contrary to the previously published paper (in which only a rough estimation of exposure levels was given), information on the cumulative eye lens doses of Polish ICs, evaluated using the best available methodology developed within the EURALOC project, will be presented.

\section{MATERIAL AND METHODS}

\section{Subject recruitment and ophthalmologic examination}

The national database (created for the EURALOC project), including socio-medical data, information on the confounders for cataract (age, gender, smoking, steroids, medical exposure, etc.) and an assessment of eye lens opacities, was used for the analysis of the prevalence of opacities among the ICs. The database was then extended with data on the median cumulative eye lens doses calculated from the distributions of doses simulated for each IC based on information on his/her work practice and procedure-specific eye lens doses.

The methodology is described in detail in the paper by Struelens et al. [13], so it appears sufficient to sketch here only the main ideas:

a) first, the probability distribution of the doses with and without ceiling suspended lead shield were created for the left and right eye, based on the ORAMED (Optimization of RAdiation protection for MEDical staff) project database and literature data;

b) then, the distributions of the reduction factors for lead glasses for both eyes, and among others for different projections, X-ray tube orientations, etc., were determined; 
c) based on the results from a) and b), the resulting distribution for each possible configuration of each given procedure type was calculated;

d) finally, using the resulting distributions and specific data from a given physician's questionnaire regarding his/ her working practice (including the type and number of procedures performed, and the protective measures employed), the individual cumulative eye lens dose distribution was established. At each step, the uncertainty estimation was performed.

The above methodology of retrospective dose estimation was verified through validation measurements carried out in clinical conditions and is also described in the quoted paper [13]. The recruitment of both the ICs and controls was conducted in 2014-2016. Out of the 115 ICs who responded positively to the information about the project and were willing to participate in the study, 69 individuals aged 38-68 years, with work practice of 5-36 years, were selected according to the criteria for inclusion (5 years of practice and age at least 38 years) and exclusion (irradiation in the region of the head and neck, cataract and the use of steroids). The control group consisted of 78 unexposed individuals of a similar age range (37-67 years). Most of them were physicians (medical doctors with specialization in occupational medicine or occupationally unexposed cardiologists) while non-physicians were unexposed employees of the Nofer Institute of Occupational Medicine (NIOM), including scientific, administrative and medical [nurses]. The ICs were recruited mainly during cardiac conferences organized in various regions of Poland while the controls were recruited predominantly during courses on occupational medicine annually organized at NIOM and during the above-mentioned cardiac conferences. All the study participants were voluntaries. A few ICs responded negatively to the invitation to participate. The refusals were related to the problem of limited vision after the eye lens examination, rather than to the idea of the project.

Both eye lenses of each study participant were examined by qualified ophthalmologists with comparable experi- ence, after the dilatation of pupils with 2 drops of $1 \%$ tropicamide, using a slit lamp, and then evaluated with the LOCS III grading system (Lens Opacities Classification System III) with a 6-level scale for nuclear opacities (both color and opalescence), and a 5-level scale for both cortical and PSC opacities [16]. The LOCS III was chosen to ensure methodological consistency with the latest studies, which is the key issue for their comparison.

The Bioethical Committee Board approved the study (Resolution No. 16/2013, date: November 11, 2013) and written informed consent was obtained from all the subjects before their participation.

\section{Data preparation and analysis}

Opacities of the lens were transformed to dichotomous categorical variables, with 2 levels: "normal" (= 0.1 , meaning normally transparent lens, treated as the reference level) and "increased opacity" (>0.1, indicating the presence of some degree of opacity in the lens).

Exposure variables were the subject group (control/ICs) or the cumulative radiation doses for the left and right eye. Additional risk factors for increased lens opacity were included in the adjusted models, i.e., gender (male [reference]/female), previous exposure to medical procedures involving radiation (no [reference]/yes) and current smoking status (no [reference]/yes). This was based on the medical knowledge of the general population from literature (see Introduction).

As the main technique of analysis, the linear logistic regression model was used to model dichotomous opacities, separately for nuclear, cortical and posterior capsular regions of the lens. The explanatory (exposure) variable of interest was the subject group. The other risk factors, i.e., age, gender, medical radiation and current smoking status, were also included in the regression models for opacity as additional explanatory variables. For the dose-effect analysis, the logistic regression model was estimated for a subset of the ICs group, with a logarithm 
of the cumulative IR dose as the main exposure variable, and with age (years), gender, medical radiation and current smoking status acting as additional explanatory variables, included as potential confounders. For sensitivity assessment of the presented results, the alternative (not shown) tabulations and regression modeling were carried out, where the categorized radiation doses ( 2 and 3 levels for the dose, with the cut points at $100 \mathrm{mSv}$ and $300 \mathrm{mSv}$ ) and age ( 2 levels, with the cut point at 45 years) were used instead of numerical variables.

Logistic regression coefficient $\beta$ for the exposure variable corresponds to the change in the logit (i.e., the natural logarithm of the odds $=\mathrm{P} /(1-\mathrm{P}))$ of the estimated probability P for "increased opacity," associated with a unitary change in the exposure variable, holding the others explanatory variables fixed. The exponential of this coefficient, $\exp (\beta)$, represents the estimated odds ratio $(\mathrm{OR})$ for increased opacity, i.e., the odds for "increased opacity" in the exposed group (the ICs) divided by the odds for "increased opacity" in the reference (control, unexposed) group.

Fisher's exact test was used for crude non-parametric assessment of the association between variables in 2 by 2 tables. Student's t-test was used for comparing the means of age, BMI and other numerical variables measured on continuous scales. In statistical tests, the results with $p<0.05$ were considered statistically significant. Statistical analyses were performed using the R software [17].

\section{RESULTS}

\section{Study population}

The characteristics of the study population is presented in Table 1. There was a statistically significant difference between the age of the ICs and the control group ( $p=$ 0.001). The mean age of the ICs was 46 years (range 34-68 years), and 50 years was the mean age in the control group (range 37-67 years).

There are generally few women working as interventional cardiologists and, therefore, $91 \%$ of the recruited cardi- ologists were men, compared to $56 \%$ of men in the control group. The difference was also statistically significant $(\mathrm{p}<0.001)$. The mean body mass index (BMI) among the ICs was $25.94 \mathrm{~kg} / \mathrm{m}^{2}$, compared to $27.33 \mathrm{~kg} / \mathrm{m}^{2}$ in the control group $(p=0.036)$. The duration of work as an IC was about 14 years $(\mathrm{SD}=6.41)$. The current smoking status was declared by $4 \%$ of the ICs and by $15 \%$ of the control subjects. The difference was statistically significant $(p=0.03)$. The number of smoked cigarettes per day was 8 in the exposed group and 15 in the control group (Table 1).

Such diseases as diabetes, high cholesterol level, high blood pressure and cancer were diagnosed and treated in 3\%, $29 \%, 23 \%$ and $3 \%$ of the ICs, respectively. The subjects from the control group declared high cholesterol levels (28\%), high blood pressure (32\%), diabetes (1\%) and cancer $(3 \%)$ as the diseases diagnosed and treated (Table 1).

Eye diseases (such as cataract, glaucoma, macular degeneration) concerned relatives of the ICs (22\%, $6 \%$ and $2 \%$, respectively) and were also declared among relatives of the subjects in the control group $(8 \%, 1 \%$ and $3 \%$, respectively) (Table 1).

Myopia was declared by $43 \%$ of the ICs and $40 \%$ of the control subjects.

Steroids taken to the eye were mentioned by almost $3 \%$ of both the ICs and the control subjects (Table 1).

The data regarding diseases in general, eye diseases and steroids taken were not statistically significant. Additionally, there were no differences in medical examinations such as the head and neck CT, and other diagnostic or treatment procedures during which the patient can be exposed to IR (Table 1).

\section{Eye examination data}

Nuclear opacities were the most common type of opacities. Left nuclear opalescence and left nuclear color opacities were found in $38 \%$ of the ICs for both types, and in $47 \%$ and $41 \%$ of the control subjects, respectively (LOCS III grades 1, 2, 3) (Table 2). Right nuclear opalescence and 
Table 1. The characteristics of the study group of interventional cardiologists in the study of 2014-2016, Poland

\begin{tabular}{|c|c|c|c|}
\hline \multirow{2}{*}{ Variable } & \multicolumn{2}{|c|}{$\begin{array}{c}\text { Participants } \\
(\mathrm{N}=147)\end{array}$} & \multirow{2}{*}{$\mathrm{p}^{\mathrm{a}}$} \\
\hline & $\begin{array}{l}\text { interventional cardiologists } \\
\qquad(\mathrm{N}=69)\end{array}$ & $\begin{array}{l}\text { controls } \\
(\mathrm{N}=78)\end{array}$ & \\
\hline Age [years] $(\mathrm{M} \pm \mathrm{SD})$ & $45.51 \pm 7.16$ & $49.68 \pm 7.14$ & 0.001 \\
\hline $\operatorname{Sex}[\mathrm{n}(\%)]$ & & & $<0.001$ \\
\hline female & $6(8.7)$ & $34(43.6)$ & \\
\hline male & $63(91.3)$ & $44(56.4)$ & \\
\hline $\mathrm{BMI}\left[\mathrm{kg} / \mathrm{m}^{2}\right](\mathrm{M} \pm \mathrm{SD})$ & $25.94 \pm 3.55$ & $27.33 \pm 4.35$ & 0.036 \\
\hline Duration of work [years] (M $\pm \mathrm{SD})$ & $13.90 \pm 6.41$ & & \\
\hline Smoking $[\mathrm{n}(\%)]$ & & & 0.06 \\
\hline never & $50(72.5)$ & $46(59.0)$ & \\
\hline past & $16(23.2)$ & $20(25.6)$ & \\
\hline current & $3(4.3)$ & $12(15.4)$ & \\
\hline Current smoking [n (\%)] & & & 0.03 \\
\hline no & $3(4.3)$ & $12(15.4)$ & \\
\hline yes & $66(95.7)$ & $66(84.4)$ & \\
\hline Smoked cigarettes [n/day] $(\mathrm{M} \pm \mathrm{SD})$ & $8.33 \pm 2.89$ & $15.36 \pm 8.14$ & 0.18 \\
\hline Have you ever smoked cigarettes? [n (\%)] & & & 0.12 \\
\hline yes & $19(27.5)$ & $32(41.0)$ & \\
\hline no & $50(72.5)$ & $46(59.0)$ & \\
\hline \multicolumn{4}{|l|}{ Diseases diagnosed and treated $[\mathrm{n}(\%)]$} \\
\hline diabetes & $2(2.9)$ & $1(1.3)$ & 0.60 \\
\hline high cholesterol level & $20(29.45)$ & $21(28.0)$ & 0.86 \\
\hline high blood pressure & $15(22.7)$ & $24(32.0)$ & 0.26 \\
\hline cancer & $2(2.9)$ & $2(2.6)$ & 1.00 \\
\hline \multicolumn{4}{|l|}{ Eye disease among relatives [n (\%)] } \\
\hline cataract & $15(21.7)$ & $6(7.7)$ & 0.23 \\
\hline glaucoma & $4(5.8)$ & $1(1.3)$ & 0.29 \\
\hline macular degeneration & $1(1.5)$ & $2(2.6)$ & 0.70 \\
\hline \multicolumn{4}{|c|}{ Have you had one of the following treatments? [n (\%)] } \\
\hline eye surgery & 0 & 0 & n.a. \\
\hline eye injury & 0 & 0 & n.a. \\
\hline uveitis & 0 & 0 & n.a. \\
\hline implantation of an artificial lens of the eye & 0 & 0 & n.a. \\
\hline myopia & $29(43.3)$ & $29(39.7)$ & 0.73 \\
\hline
\end{tabular}


Table 1. The characteristics of the study group of interventional cardiologists in the study of 2014-2016, Poland - cont.

\begin{tabular}{|c|c|c|c|}
\hline \multirow{2}{*}{ Variable } & \multicolumn{2}{|c|}{$\begin{array}{l}\text { Participants } \\
(\mathrm{N}=147)\end{array}$} & \multirow{2}{*}{$\mathrm{p}^{\mathrm{a}}$} \\
\hline & $\begin{array}{l}\text { interventional cardiologists } \\
\qquad(\mathrm{N}=69)\end{array}$ & $\begin{array}{l}\text { controls } \\
(\mathrm{N}=78)\end{array}$ & \\
\hline Steroids taken ever [n (\%)] & & & 0.90 \\
\hline yes & $2(2.9)$ & $2(2.6)$ & \\
\hline no & $67(97.1)$ & $76(97.4)$ & \\
\hline \multicolumn{4}{|l|}{ Medical examination [n (\%)] } \\
\hline head CT & $13(19.10)$ & $11(14.35)$ & 0.51 \\
\hline neck CT & $5(7.45)$ & $9(11.80)$ & 0.41 \\
\hline head PET-CT & 0 & 0 & n.a. \\
\hline neck PET-CT & 0 & 0 & n.a. \\
\hline $\begin{array}{l}\text { Diagnostic examination or treatment } \\
\text { with radio-nuclides [n }(\%)]\end{array}$ & & & 0.67 \\
\hline yes & $3(4.3)$ & $2(2.56)$ & \\
\hline no & $65(94.2)$ & $74(94.87)$ & \\
\hline data unknown & $1(1.4)$ & $2(2.56)$ & \\
\hline Cerebral angiography $[\mathrm{n}(\%)]$ & & & 0.50 \\
\hline yes & $0(0)$ & $2(2.56)$ & \\
\hline no & $69(100)$ & $75(96.15)$ & \\
\hline data unknown & $0(0)$ & $1(1.28)$ & \\
\hline $\begin{array}{l}\text { Have you ever had an interventional } \\
\text { radiology/cardiology procedure? }\end{array}$ & & & 1.00 \\
\hline yes & $1(1.45)$ & $1(1.28)$ & \\
\hline no & $67(97.10)$ & $76(97.44)$ & \\
\hline data unknown & $1(1.45)$ & $1(1.28)$ & \\
\hline $\begin{array}{l}\text { Have you ever undergone medical interventions } \\
\text { with fluoroscopy of the head? [n }(\%)]\end{array}$ & & & 1.00 \\
\hline yes & $0(0)$ & $1(1.28)$ & \\
\hline no & $68(98.6)$ & $76(97.44)$ & \\
\hline data unknown & $1(1.4)$ & $1(1.28)$ & \\
\hline
\end{tabular}

a The p-values for the test of equality of the means in the control and ICs groups (for continuous characteristics) or Fisher's exact test for association with the subject group (for binary characteristics).

n.a. - not applicable.

Bolded - results with $\mathrm{p}<0.05$ considered to be statistically significant.

right nuclear color opacities were observed in $35 \%$ and $36 \%$ of the exposed subjects, compared to $47 \%$ and $42 \%$ of the unexposed subjects, respectively. There were no differences in either nuclear opacities among the study groups.
Left and right cortical opacities were found in $25 \%$ and $26 \%$ of the ICs, respectively, and in $28 \%$ of the controls for both eyes (Table 2). The left and right posterior subcapsular opacities were rare and accounted for $4 \%$ and $3 \%$ of 
Table 2. The eye lens opacities detected in an ophthalmological examination by study group in the study of 2014-2016, Poland

\begin{tabular}{|c|c|c|c|}
\hline \multirow[b]{2}{*}{ Opacity level } & \multicolumn{2}{|c|}{$\begin{array}{c}\text { Participants } \\
{[\mathrm{n}(\%)]}\end{array}$} & \multirow[b]{2}{*}{$\mathrm{p}$} \\
\hline & $\begin{array}{c}\text { interventional } \\
\text { cardiologists } \\
(\mathrm{N}=69)\end{array}$ & $\begin{array}{l}\text { controls } \\
(\mathrm{N}=78)\end{array}$ & \\
\hline \multicolumn{4}{|l|}{ Left } \\
\hline nuclear opalescence & & & 0.32 \\
\hline 0.1 & $43(62.3)$ & $42(53.2)$ & \\
\hline $1-3$ & $26(37.7)$ & $36(46.8)$ & \\
\hline nuclear color & & & 0.74 \\
\hline 0.1 & $43(62.3)$ & $46(59.0)$ & \\
\hline $1-3$ & $26(37.7)$ & $32(41.0)$ & \\
\hline cortical & & & 0.71 \\
\hline 0.1 & $52(75.4)$ & $56(71.8)$ & \\
\hline $1-2$ & $17(24.6)$ & $22(28.2)$ & \\
\hline posterior subcapsular & & & 1.00 \\
\hline 0.1 & $66(95.7)$ & $75(96.2)$ & \\
\hline 1 & $3(4.3)$ & $3(3.8)$ & \\
\hline \multicolumn{4}{|l|}{ Right } \\
\hline nuclear opalescence & & & 0.13 \\
\hline 0.1 & $45(65.2)$ & $41(52.6)$ & \\
\hline $1-3$ & $24(34.8)$ & $37(47.4)$ & \\
\hline nuclear color & & & 0.50 \\
\hline 0.1 & $44(63.8)$ & $45(57.7)$ & \\
\hline $1-3$ & $25(36.2)$ & $33(42.3)$ & \\
\hline cortical & & & 0.85 \\
\hline 0.1 & $51(73.9)$ & $56(71.8)$ & \\
\hline $1-2$ & $18(26.1)$ & $22(28.2)$ & \\
\hline posterior subcapsular & & & 1.00 \\
\hline 0.1 & $67(97.1)$ & $76(97.4)$ & \\
\hline 1 & $2(2.9)$ & $2(2.6)$ & \\
\hline
\end{tabular}

Cases with normal (=grade 0.1 ) and increased (grade 1 to 2 or 3 ) opacity, with p-values of Fisher's exact test for the association between opacity and the subject group.

the ICs, respectively, and for $4 \%$ and $3 \%$ of the controls, respectively. The differences in the frequency of posterior subcapsular opacities and cortical opacities were not statistically significant among the study groups.

\section{Cumulative eye lens doses}

Table 3 shows the eye lens doses of the ICs, accumulated throughout their entire careers. As the doses are very small, the authors also presented the distribution over 
Table 3. Summary statistics for the cumulative doses for the left and right eye for all cardiologists (all ICs) and the subgroups of cardiologists working in electrophysiology and hemodynamic rooms in the study of 2014-2016, Poland

\begin{tabular}{lcccccc}
\hline \multirow{2}{*}{ ICs } & \multicolumn{9}{c}{$\begin{array}{c}\text { Dose } \\
{[\mathrm{mSv}]}\end{array}$} \\
\cline { 2 - 7 } & \multicolumn{2}{c}{ range } & \multicolumn{2}{c}{ M \pm SD } & \multicolumn{2}{c}{ Me } \\
\cline { 2 - 7 } & left eye & right eye & left eye & right eye & left eye & right eye \\
\hline All ICs & $7-1713$ & $4-687$ & $224 \pm 358$ & $85 \pm 106$ & 83 & 48 \\
Hemodynamists & $7-1713$ & $6-687$ & $357 \pm 421$ & $128 \pm 127$ & 189 & 79 \\
Electrophysiologists & $7-300$ & $4-163$ & $60 \pm 75$ & $47 \pm 37$ & 27 & 38 \\
\hline
\end{tabular}

doses (Figure 1) for better orientation. The median dose distributions are shown firstly for all the ICs and then separately for physicians working in electrophysiology rooms and in hemodynamic rooms. The latter group also includes physicians performing electrophysiology proce-
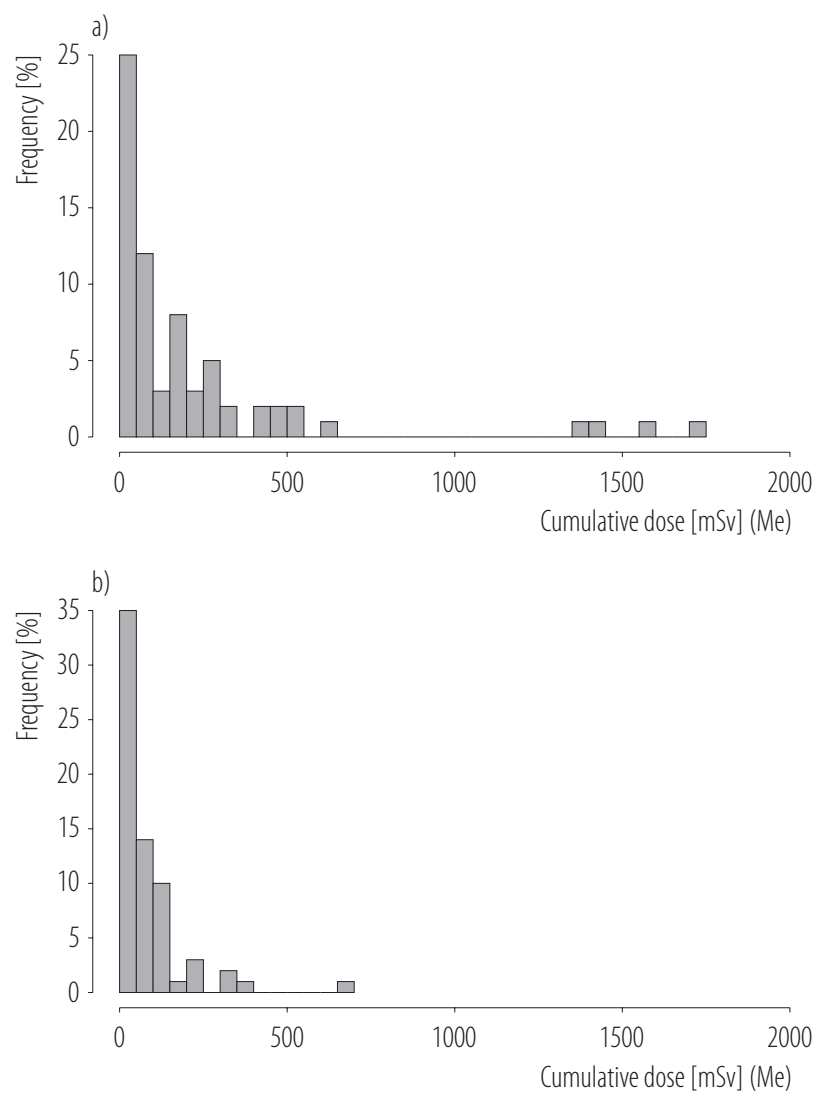

Figure 1. The distribution of cumulative doses to the left and right eye lens of interventional cardiologists in the study of 2014-2016, Poland dures or interventional radiology procedures, in addition to hemodynamic ones.

The average cumulative doses to eye lens for the ICs in general were $224 \mathrm{mSv}$ and $85 \mathrm{mSv}$ for the left and right eye, respectively. For only 7 ICs, all working in hemodynamic rooms, the doses exceeded $500 \mathrm{mSv}$ (revised by the ICRP threshold dose for cataract) for at least the left eye, and the maximum evaluated dose was $1713 \mathrm{mSv}$ (for the left eye lens). In general, the doses received by physicians working in hemodynamic rooms were statistically significantly higher $(\mathrm{p}<0.001)$ for both eyes than those received in electrophysiology rooms (the average median dose for the left eye $357 \mathrm{mSv}$ vs. $60 \mathrm{mSv}$, and for the right eye $128 \mathrm{mSv}$ vs. $47 \mathrm{mSv}$ ). For both electrophysiologists and hemodynamists, the higher doses were accumulated in the left eye lens (the X-ray tube is more often on the left side of the physicians), with an exception that the exposure between both eye lens was significantly greater for physicians working in hemodynamic rooms due to their more asymmetric position with regard to the X-ray tube, compared with electrophysiologists; the ratio between the dose averages for the left and right eye lens dose was 2.8 and 1.3 for hemodynamists and electrophysiologists, respectively.

\section{The association between exposure to ionizing radiation among interventional cardiologists and eye lens opacities} After controlling for age, gender, current smoking status and medical IR, there were no significant differences in 
Table 4. The association between exposure to ionizing radiation among interventional cardiologists and eye lens opacities, with the subject group as the exposure variable (the ICs vs. the control group) in the study of 2014-2016, Poland

\begin{tabular}{lcc}
\hline \multicolumn{1}{c}{ Opacity type } & OR $(95 \% \mathrm{CI})$ & $\mathrm{p}$ \\
\hline Left & & \\
$\quad$ nuclear opalescence & $1.91(0.76-5.03)$ & 0.18 \\
nuclear color & $1.91(0.79-4.85)$ & 0.16 \\
cortical & $0.98(0.40-2.40)$ & 0.96 \\
$\quad$ posterior subcapsular & $1.93(0.23-17.41)$ & 0.54 \\
Right & & \\
nuclear opalescence & $1.65(0.65-4.38)$ & 0.30 \\
nuclear color & $1.80(0.74-4.58)$ & 0.20 \\
cortical & $1.07(0.44-2.64)$ & 0.88 \\
$\quad$ posterior subcapsular & $1.51(0.12-21.56)$ & 0.75 \\
Pooled both sides and all types & $1.47(0.62-3.59)$ & 0.39 \\
$\quad$ (any-side any-type) & & \\
\hline
\end{tabular}

Adjusted for: age (years) and binary variables: subjects' gender (levels: male [reference]/female), current smoking status (levels: no [reference]/yes), exposure to any medical procedures involving IR as the patient (levels: no [reference]/yes). the left and right nuclear (opalescence $\mathrm{p}=0.18$ and $\mathrm{p}=$ 0.30 , respectively; color $\mathrm{p}=0.16$ and $\mathrm{p}=0.20$, respectively), cortical ( $p=0.96$ and $p=0.88$, respectively) and posterior subcapsular $(\mathrm{p}=0.54$ and $\mathrm{p}=0.75$, respectively) opacities in the ICs group, compared with the controls (Table 4). After all the types of opacities were included in one category and the model was adjusted for confounding variables (age, gender, current smoking and medical IR), there were no statistically significant differences in the opacities occurring in the exposed vs. unexposed individuals.

\section{Dose-response analysis}

The cumulative dose of IR among the ICs was not related to any eye opacities (nuclear opalescence, color, cortical, posterior subcapsular) in the right and left eye (Table 5). The attempted categorical analysis, including the classification of the ICs to 2 groups by age and to 3 groups by estimated doses, gave the same result in quality terms (Table 6).

Table 5. The association between opacities and the binary (i.e., base 2) logarithm of the cumulative dose of ionizing radiation from occupational exposure among interventional cardiologists $(\mathrm{N}=69)$ in the study of 2014-2016, Poland

\begin{tabular}{lcccc}
\hline \multirow{2}{*}{ Cumulative dose } & \multicolumn{2}{c}{ Crude } & Adjusted* \\
\cline { 2 - 4 } & OR (95\% CI) & $\mathrm{p}$ & OR (95\% CI) & $\mathrm{p}$ \\
\hline Left & & & & \\
$\quad$ nuclear opalescence & $1.14(0.90-1.47)$ & 0.290 & $0.93(0.67-1.29)$ & 0.665 \\
nuclear color & $1.08(0.85-1.39)$ & 0.522 & $0.94(0.69-1.28)$ & 0.681 \\
cortical & $0.88(0.65-1.15)$ & 0.354 & $0.83(0.60-1.16)$ & 0.280 \\
posterior subcapsular & $0.90(0.47-1.61)$ & 0.725 & $0.72(0.36-1.32)$ & 0.293 \\
Right & & & & \\
nuclear opalescence & $1.34(0.94-1.97)$ & 0.112 & $0.86(0.53-1.42)$ & 0.553 \\
nuclear color & $1.29(0.91-1.87)$ & 0.167 & $0.97(0.61-1.56)$ & 0.883 \\
cortical & $0.79(0.52-1.16)$ & 0.235 & $0.62(0.36-1.01)$ & 0.063 \\
posterior subcapsular & $0.30(0.07-0.92)$ & 0.059 & $0.34(0.06-1.06)$ & 0.107 \\
Any left opacity & $1.11(0.87-1.41)$ & 0.406 & $0.99(0.73-1.34)$ & 0.947 \\
Any right opacity & $1.18(0.85-1.67)$ & 0.334 & $0.92(0.59-1.43)$ & 0.701 \\
\hline
\end{tabular}

* Adjusted for age, gender, medical radiation and current smoking.

The OR column indicates changes in the odds for increased opacity in response to 1 unit change of the $\log _{2}$ (dose), i.e., to doubling the dose. The dose ipsilateral (left or right) to the eye was taken as exposure. The validity of these estimates is limited to the dose ranges presented in Table 3. 
Table 6. The dose-response model coefficients of the linear logistic regression model with the occupational radiation dose as the categorical variable with the following 3 levels: 0-100 $\mathrm{mSv}$ (the reference level), $100-300 \mathrm{mSv}$ (the middle level), $>300 \mathrm{mSv}$ (the highest level) in the study of 2014-2016, Poland

\begin{tabular}{ccc}
\hline Opacity type/Predictor & OR $(95 \%$ CI $)$ & $\mathrm{p}$ \\
\hline Left nuclear opalescence & & \\
dose left $(0,100]$ & reference & \\
dose left $(100,300]$ & $1.03(0.23-4.44)$ & 0.965 \\
dose left $\left(300,1.71 \times 10^{3}\right]$ & $0.51(0.08-2.68)$ & 0.440 \\
Left nuclear color & & \\
dose left $(0,100]$ & reference & \\
dose left $(100,300]$ & $1.01(0.24-3.99)$ & 0.989 \\
dose left $\left(300,1.71 \times 10^{3}\right]$ & $0.39(0.06-1.99)$ & 0.279 \\
Left cortical & & \\
dose left $(0,100]$ & reference & \\
dose left $(100,300]$ & $0.83(0.19-3.35)$ & 0.801 \\
dose left $\left(300,1.71 \times 10^{3}\right]$ & $0.40(0.05-2.28)$ & 0.332 \\
Right nuclear opalescence & & \\
dose right $(0,100]$ & reference & \\
dose right $(100,300]$ & $0.37(0.05-1.94)$ & 0.271 \\
dose right $(300,687]$ & $0.61(0.03-18.79)$ & 0.744 \\
Right nuclear color & & \\
dose right $(0,100]$ & reference & \\
dose right $(100,300]$ & $0.35(0.05-1.71)$ & 0.227 \\
dose right $(300,687]$ & $0.24(0.01-3.74)$ & 0.315 \\
Right cortical & & \\
dose right $(0,100]$ & reference & \\
dose right $(100,300]$ & $0.48(0.08-2.29)$ & 0.385 \\
dose right $(300,687]$ & $0.54(0.02-8.19)$ & 0.673 \\
\hline
\end{tabular}

To improve the stability of the model, the adjustment for smoking and gender was dropped, and the data were restricted to non-smoking male cardiologists ( $\mathrm{N}=61$ ), adjusted only for age (years) and past exposure to medical procedures involving ionizing radiation (no/yes). Opacity of the posterior subcapsular (PSC) type was not reliably estimable and is not shown.

\section{DISSCUSION}

No association was found between lens opacities and IR in the cohort of the ICs occupationally exposed to X-rays. However, it should be noted that the inter-compared groups differed in terms of the main factor parameters.
In addition, no differences were found in the incidence of opacities (for all their types) between the left and right eye lens of the ICs in spite of almost 3-fold differences between the average doses. In such a case, the other risk factors are the same which suggests that the influence of sex, age and other factors is not crucial when the risk coming from low doses is investigated. Furthermore, no differences in the frequency of opacities were found between electrophysiologists and hemodynamists although even 6-fold differences in the doses were estimated. This might suggest that the levels of exposure observed in the present study did not significantly influence the development of opacities. This conclusion is in agreement with the outcome of a Finish study [18] in which no association was found at the low exposure level of $111 \mathrm{mSv}$ in average terms.

Moreover, citing the conclusion of Auvinen [18], these findings do not contradict the results presented in other papers reporting the occupational radiation exposure levels to the eye lens of the ICs and the related increased risk of opacities [19-21], as the doses presented are much lower, and also lower than the new dose threshold of 0.5 Gy for detectable opacities. In particular, the cumulative doses assessed in this study are almost 2 times lower than the ones in the French O'CLOC study calculated using a similar approach; $224 \mathrm{mSv}$ in the Polish study vs. $423 \mathrm{mSv}$ in the French study. This could be explained by the lower average age of the ICs in the Polish cohort and, consequently, a shorter duration of their work, which was 14 years, while in the French cohort it was 22 years [12], with a comparable annual workload and the use of protective tools [12,22].

The relationship between opacity and IR may be hindered by the way the measurements were obtained. The inter-observer variability in the grading of the opacities by 4 ophthalmologists is one of the limitations. More sensitive methods for eye lens opacities evaluation (detecting changes even at the molecular level before any clinical manifestation) could be used, but then the assessment of potential confounders for cataract should be more precise 
as well. This would make the retrospective epidemiological study on cataract very challenging. The cumulative dose was approximated by the best currently available, and yet rather complex, process.

Generally, the inherent difficulties in the studies of the effects of low doses are related to high uncertainties in the assessment of the doses in this range and a much lower incidence of cases with a more considerable effect than it is observed for substantially higher doses. In particular, in the present study, grade 1 was observed most frequently for all types of opacities. The maximum grade for PSC opacity, usually related to IR, was also 1 , while for the other types the maximum was 2 for cortical and 3 for nuclear opacity. For this reason, the final result presented in this paper might be biased by a relatively small study sample size for such exposure levels, and the relationship between opacities and IR cannot be definitely excluded.

Nonetheless, to make their conclusions as sound as possible, the authors would like to stress that they used the best methodology available at present, including all known non-radiation confounders. The only factors that have not been taken into account are the role of a healthy diet and UV exposure. However, it can be assumed that physicians are a specific social group aware of both the role of a proper diet (which might have resulted in lowering the risk) and the harmful effect of UV radiation (therefore, if necessary, they tend to protect their eyes with sunglasses with UVB filters).

This paper is more focused on the exposure levels and the cataract risk in the group of Polish ICs than on responding to fundamental questions concerning cataract formation. However, regarding the latter issue, this work also has some impact. The study results indicate that the latency period for opacities for doses of about $150 \mathrm{mSv}$ is $>5$ years, and possibly even > 10 years; the average exposure for 67 ICs who declared $>5$ years of work during the first 5 years of their practice was about $150 \mathrm{mSv}$ (in the left eye lens), while for those 45 ICs who declared $>10$ years it was about $170 \mathrm{mSv}$ during the first 10 years of their work. In this context, increased age and a longer exposure period should rather be used as inclusion criteria for a bigger study cohort in future studies.

\section{CONCLUSIONS}

No association between lens opacities of any type and IR in the cohort of Polish interventional cardiologists was found. Therefore, it is possible that IR does not influence significantly the development of cataract when the exposure levels are relatively low, as was the case in this research (the average doses to the left and right eye of about $220 \mathrm{mSv}$ and $80 \mathrm{mSv}$, respectively).

Nonetheless, the obtained results should be interpreted with caution due to the sample size (which, although quite considerable compared to the previous papers, might still prove too small for the analysis of the effects in the dose range estimated in this study). Therefore, no definite conclusion can be drawn based on this study and the slight increase in the risk cannot be ruled out either. Even so, this study indicates that the initial stages of lens opacification after exposure to the dose levels observed in this study should not affect significantly the quality of life because most of the physicians had grade 1 opacity which is so mild that they are not even aware of it.

However, the changes may progressively increase with the IR dose and time, and their severity should be verified in future follow-up studies as the mechanism of cataract formation has not been well understood yet. The results of ongoing mechanistic studies on cataract as well as the epidemiological multi-centre EURALOC study might also shed light on the biological process of cataract formation and related risks in the low-dose range.

\section{ACKNOWLEDGMENTS}

The authors would like to thank all the interventional cardiologist and physicians who participated in the study and all others who supported this study. 


\section{REFERENCES}

1. Ainsbury EA, Barnard S, Bright S, Dalke C, Jarrin M, Kunze S, et al. Ionizing radiation induced cataracts: Recent biological and mechanistic developments and perspectives for future research. Mutat Res. 2016;770(Pt B):238-61, https:// doi.org/10.1016/j.mrrev.2016.07.010.

2. Cumming RG, Mitchell P. Alcohol, smoking, and cataracts: the Blue Mountains Eye Study. Arch Ophthalmol. 1997; 115(10):1296-303.

3. Gong Y, Feng K, Yan N, Xu Y, Pan CW. Different amounts of alcohol consumption and cataract: a meta-analysis. Optom Vis Sci. 2015;92(4):471-9, https://doi.org/10.1097/OPX. 0000000000000558.

4. Hiratsuka Y, Ono K, Murakami A. Alcohol use and cataract. Curr Drug Abuse Rev. 2009;2(3):226-9.

5. Raju P, George R, Ve Ramesh S, Arvind H, Baskaran M, Vijaja L. Influence of tobacco use on cataract development. Br J Ophthalmol. 2006;90(11):1374-7, https://doi.org/10.1136/ bjo.2006.097295.

6. Weikel KA, Garber C, Baburins A, Taylor A. Nutritional modulation of cataract Nutr Rev. 2014;72(1):30-47, https:/ doi.org/10.1111/nure.12077.

7. Wei L, Liang G, Cai C, Lv J. Association of vitamin C with the risk of age-related cataract: a meta-analysis. Acta Ophthalmol. 2016;94(3):e170-6, https://doi.org/10.1111/aos.12688.

8. Jacob S, Michel M, Brézin AP, Laurier D, Bernier MO. Ionizing Radiation as a Risk Factor for Cataract: What about Low-Dose Effects? J Clinic Experiment Ophthalmol. 2011;S1:005, https://doi.org/10.4172/2155-9570.

9. Henk JM, Whitelocke RA, Warrington AP, Bessel EM. Radiation dose to the lens and cataract formation. Int J Radiat Oncol Biol Phys. 1993;25(5):815-20.

10. Minamoto A, Taniguchi H, Yoshitani N, Mukai S, Yokoyama T, Kumagami T. Cataract in atomic bomb survivors. Int J Radiat Biol. 2004;80(5):339-45.

11. Hammer GP, Scheidemann-Wesp U, Samkange-Zeeb F, Wicke H, Neriishi K, Blettner M. Occupational exposure to low doses of ionizing radiation and cataract development: a systematic literature review and perspectives on future studies. Radiat Environ Biophys. 2013;52(3):303-19, https:// doi.org/10.1007/s00411-013-0477-6.

12. Jacob S, Donadille L, Maccia C, Barr O, Boveda S, Lauriel $\mathrm{D}$, et al. Eye lens radiation exposure to interventional cardiologists: a retrospective assessment of cumulative doses. Radiat Prot Dosimetry. 2013;153(3):282-93, https://doi. org/10.1093/rpd/ncs116.

13. Struelens L, Dabin J, Carinou E, Ascounis P, Ciraj-Bjelac O, Domienik-Andrzejewska J, et al. Radiation-Induced Lens Opacities among Interventional Cardiologists: Retrospective Assessment of Cumulative Eye Lens Doses. Radiat Res. 2018;189(4):399-408, https://doi.org/10.1667/RR14970.1.

14. Authors on behalf of ICRP, Stewart FA, Akleyev AV, HauerJensen M, Hendry JH, Kleiman NJ, Macvittie TJ, et al. ICRP Publication 118: ICRP Statement on Tissue Reactions / Early and Late Effects of Radiation in Normal Tissues and Organs - Threshold Doses for Tissue Reactions in a Radiation Protection Context. Ann ICRP. 2012;41(1/2), https:// doi.org/10.1016/j.icrp.2012.02.001.

15. Domienik J, Gryglak S, Jurewicz J. Characteristics of interventional cardiologists and their work practices for the study on radiation-induced lens opacities based on the methodology developed by ELDO - preliminary results. J Radiat Res. 2017;57(4):431-7, https://doi.org/10.1093/jrr/rrw019.

16. Chylack LT, Wolfe JK, Singer DM, Leske MC, Bullimore MA, Bailey IL, et al. The Lens Opacities Classification System III. The Longitudinal Study of Cataract Study Group. Arch Ophthalmol. 1993;111(6):831-6.

17. R Core Team. R: A language and environment for statistical computing. Vienna: R Foundation for Statistical Computing; 2017.

18. Auvinen A, Kivelä T, Heinävaara S, Mrena S. Eye Lens Opacities Among Physicians Occupationally Exposed to Ionizing Radiation. Ann Occup Hyg. 2015;59(7):945-8, https://doi.org/10.1093/annhyg/mev022.

19. Ciraj-Bjelac O, Rehani MM, Sim KH, Liew HB, Vano E, Kleiman NJ. Risk for radiation-induced cataract for staff 
in interventional cardiology: is there reason for concern? Catheter Cardiovasc Interv. 2010;76(6):826-34, https://doi. org/10.1002/ccd.22670.

20. Vano E, Kleiman NJ, Duran A, Rehani MM, Echeverri D, Cabrera M. Radiation cataract risk in interventional cardiology personnel. Radiat Res. 2010;174(4):490-5, https://doi. org/10.1667/RR2207.1.

21. Jacob S, Boveda S, Bar O, Brézin A, Maccia C, Laurier D, et al. Interventional cardiologists and risk of radiation-induced cataract: Results of a French multicenter observational study. Int J Cardiol. 2013;167(5):1843-7, https://doi.org/10.1016/ j.ijcard.2012.04.124.

22. Domienik-Andrzejewska J, Ciraj-Bjelac O, Askounis P, Covens P, Dragusin O, Jacob S, et al. Past and present work practices of European interventional cardiologists in the context of radiation protection of the eye lens - results of the EURALOC study. J Radiol Prot. 2018;38(3), https://doi. org/10.1088/1361-6498/aac64b.

This work is available in Open Access model and licensed under a Creative Commons Attribution-NonCommercial 3.0 Poland License - http://creativecommons.org/ licenses/by-nc/3.0/pl/deed.en. 